\title{
¿Por qué hay tan pocas científicas y tecnólogas?
}

CP 2015 , Vol.4-Nº8 (Monográfico II), pp. 57-59. ISSN 2014-6752. Girona (Catalunya). BERBEL SÁNCHEZ, Sara: ¿Por qué hay tan pocas científicas y tecnólogas?. Recibido: 05/11/2015 - Aceptado: 20/11/2015

Género, ciencia y tecnologías de la información

Directoras: Cecilia Castaño y Juliet Webster

Autoras: Milagros Sáinz, Ana M. González Ramos, Lidia Arroyo Prieto, Nuria Vergés Bosch, Jörg Müller y Beatriz Revelles Benavente

Barcelona.

Editorial Aresta, 2014.

259 páginas

ISBN 978-84-941456-6-7

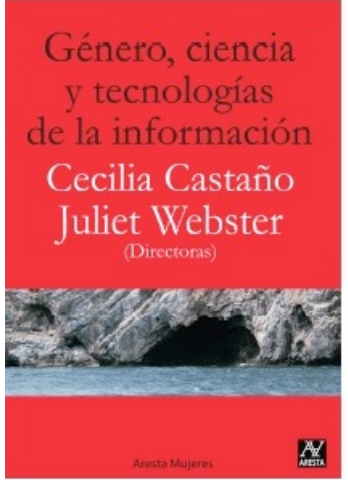

\section{Sara BERBEL SÁNCHEZ}

Directora de Empowerment Hub.saraberbels@gmail.com

El libro que reseñamos trata de dar respuesta a esta pregunta, al tiempo que describe la relación existente entre las mujeres, la ciencia y la tecnología. Y lo hace desde una perspectiva rigurosa pero no estrictamente académica, en donde los datos aportados se combinan perfectamente con una redacción divulgativa, acompañada de gráficos y ejemplos, que pretende alcanzar al gran público. La obra es el compendio de ocho artículos firmados por diferentes autoras en los que se abordan las diferentes cuestiones relacionadas con la tecnología y el género tales como el rol femenino en la ciencia contemporánea, la inclusión digital de las mujeres de clase trabajadora o incluso casos prácticos de presencia relevante de mujeres en las TIC.

El dilema que orienta todos los capítulos del libro se basa en la contradicción que supone que más de la mitad de los estudiantes universitarios sean mujeres y, sin embargo, muy pocas de ellas están presentes en el sistema científico y tecnológico. Esta realidad genera un problema de equidad y eficiencia para nuestra sociedad. Por una parte, porque se impide a las mujeres el acceso a puestos creativos, atractivos y bien remunerados, pero por otra porque la ciencia y la tecnología no se benefician de las valiosas visiones y aportaciones que pudieran incorporar las mujeres con su trabajo. Está ampliamente contrastado el beneficio que supone para las organizaciones contar con equipos mixtos en donde pueda expresarse el talento de todos sus miembros. Nos hallamos, en consecuencia, ante una situación negativa para todo el mundo.

Las autoras tratan de indagar en las causas que generan esta ausencia de mujeres en la ciencia y la tecnología. De entrada, hay una percepción social de que a las mujeres no les interesa la ciencia y, por tanto, si no están presentes es porque no se dedican suficientemente a ello; no se percibe, en consecuencia, la situación como problemática. Sin embargo, los estudios realizados por las propias autoras muestran que el origen de esta ausencia no es tan sencillo. De hecho, los análisis realizados constatan que a la edad de 15 años chicas y chicos tienen las mismas capacidades $y$ 
preferencias en ciencia y tecnología pero a medida que crecen y se hacen adultos, las chicas abandonan estas materias en favor de otras más en la línea de las Humanidades. Cuando llegan a la Universidad, el número de mujeres científicas es ya seis veces inferior al masculino y aún es más grave en las ingenierías. Este desequilibrio persiste en la industria ya que se observa que el personal femenino en I+D supone menos de un $20 \%$ en los sectores tecnológicos, además de que los sueldos son menores (brecha salarial) y los puestos de responsabilidad ocupados por mujeres no alcanzan el 30\%.

¿Cuáles son los motivos de esta divergencia tan enorme que se produce a partir de la adolescencia? Diríase que un conglomerado de factores se conjuran para "expulsar" a las mujeres de la ciencia y la tecnología. Las autoras destacan, entre los más significativos, la influencia del profesorado, padres y amigos que alientan a las chicas a estudios más "sociales" de acuerdo con los estereotipos más tradicionales a los que resulta muy difícil resistirse. También analizan el modelo de progresión y de excelencia en la ciencia que hace muy difícil el avance profesional de las mujeres al estar pensadas las publicaciones, la movilidad internacional, las redes profesionales e incluso la obtención de fondos de subvención desde una perspectiva masculina $\mathrm{o}$ androcéntrica.

Un tercer aspecto que puede convertirse en un obstáculo para la progresión científica de las mujeres es la propia organización y diseño de las tecnologías de la información y la comunicación (TIC) ya que a menudo reproducen las viejas formas de desigualdad de género en el acceso y en el uso de la red (la llamada "segunda brecha digital"). Aquí las autoras, sin embargo, hacen hincapié en las posibilidades que tienen las TIC de convertirse, por el contrario, en elementos de inclusión, participación y empoderamiento para las mujeres, sobre todo por la vía de la educación y el empleo.
Por último, una de las barreras más importantes y difíciles de mover para lograr el acceso y permanencia de las mujeres en el ámbito científico es la dificultad de conciliar la vida personal y familiar con la profesional. La dedicación "full time" que se suele exigir en la investigación y en los puestos de decisión científicos es denunciada por las mujeres del ámbito como un modelo obsoleto que no permite la armonía con otros aspectos de la vida, igualmente necesarios y deseables para los seres humanos.

Pese a que el libro detalla con profundidad los obstáculos que las mujeres hallan en estos momentos para estar presentes en el ámbito científico y tecnológico no puede deducirse de ello que sea una obra con una perspectiva negativa, sino al contrario. Las autoras muestran los déficits actuales precisamente para mostrar las posibilidades de superarlos y aportan ideas y experiencias que puedan permitir su eliminación. De hecho, el libro acaba con un capítulo dedicado a la escritora premio Nóbel Tony Morrison en relación a su presencia en las redes sociales. A modo de caso práctico, se muestra la trayectoria de una autora famosa por denunciar desde la literatura las injusticias sociales que utiliza la red de Facebook como herramienta de empoderamiento de la lucha feminista, potenciando con su ejemplo la generación de muchas y diversas comunidades de afinidades entre las mujeres.

Nos hallamos, en conclusión, ante un libro que logra su objetivo principal con creces: hacer visible la ausencia de mujeres en el mundo científico y tecnológico y apuntar las fórmulas para corregir esta situación. Su estilo claro y riguroso, así como la novedad de los resultados que aporta, ayuda a leerlo con gran interés de principio a fin $y$, sin duda, puede llegar a convertirse en un instrumento imprescindible para profesionales de la educación en todos los niveles de enseñanza. Sería deseable una segunda parte dentro de unos años para 
comprobar la evolución y desarrollo de los múltiples aspectos que señalan, no solo en beneficio de las mujeres científicas y tecnólogas, sino de la sociedad en su conjunto.

\section{Forma de citación}

BERBEL SÁNCHEZ, Sara: ¿Por qué hay tan pocas científicas y tecnólogas?. Revista Communication Papers, $\mathrm{N}^{\circ} 8$ (Monográfico II), páginas xxx a xxx. Departamento de Filología y Comunicación de la Universidad de Girona. Recuperado el de de 2 de: http://www.communicationpapers.es 